\title{
Quantitative two-dimensional thin-layer chromatography using a diode-array detector
}

\author{
Prof. Dr. rer. nat. Bernd Spangenberg \\ Fakultät Maschinenbau \\ und Verfahrenstechnik $(M+V)$ \\ Badstraße 24 \\ 77652 Offenburg \\ Tel. 0781 205-101 \\ E-Mail: Spangenberg@hs-offenburg.de
}

\section{5: Geboren in Remscheid}

Studium der Chemie und Philosophie an der Universität Marburg 1983: Diplom in Chemie, 1987 Promotion über neue Reaktionen von Sulfenen am Pharmazeutischen Institut der Universität Marburg 1988: Eintritt in die E. Scheurich Pharmwerk GmbH als Laborleiter, Leiter der Abteilung analytische Forschung und Entwicklung, stellvertretender Kontrollleiter 1990: Wechsel zur EBULON AG,

Basel als Leiter der Entwicklungsanalytik 1991: Professor an der Hochschule Offenburg, Leiter des Labors für Analytik und Umweltanalytik

Seit 2007: Editor-in-Chief von Journal of Planar Chromatography Lehrgebiete: Analytik, Umweltanalytik, Abfall- und Recyclingtechnik Mitglied des Instituts für Angewandte Forschung (IAF) der Hochschule Offenburg Forschungsgebiete: Chemometrie, Trenntechniken, Dünnschichtchromatographie

\subsection{Quantitative two-dimensional thin-layer chromatography using a diode-array detector}

Barbara Milz B. SC.

Prof. Dr. rer. nat. Bernd Spangenberg

\begin{abstract}
Abstrakt
Wir präsentieren die weltweit erste Auswertung einer zweidimensional entwickelten HPTLC-Platte (2D-HPTLC) mit Hilfe eines Diodenarray-Scanners. Das System erreicht eine räumliche Plattenauflösung von $250 \mu \mathrm{m}$. Es können Absorptions- und Fluoreszenzspektren im Wellenlängenbereich von 190 bis 1000 nm mit einer spektralen Auflösung von besser als $1 \mathrm{~nm}$ gemessen werden. Eine Trennzahl von 259 wurde erreicht. Damit zeigt die Methode bessere Trenneigenschaften als die meisten HPLC-Systeme. Der Nachteil der 2D-Auswertung ist der hohe Zeitbedarf von über 3 Stunden für eine Plattenmessung.
\end{abstract}

\section{Introduction}

Generally all chromatographic methods can be divided into two main separation groups: time and space. Thin layer chromatography as a space separation method is by far the simplest separation technique considered in terms of equipment and performance [1]. Multidimensional chromatography is the most powerful tool for separations [2]. The two-dimensional thin-layer chromatography (2D-TLC) technique is one of the most versatile methods of TLC development. The first application of the two- dimensional chromatographic method as paper chromatography was reported in 1944 by Consden, Gordon, and Martin [1 - 3]. Since that time, this method has been mostly used for the separation of a large number of compounds that cannot be separated in a single dimension TLC experiment. In the first review on this topic G. Guiochon reported numerous applications of this technique [3]. The greatest dispersion of spots over the TLC plate is obtained when the chromatogram is developed in two orthogonal modes. That is the case when in the first direction a normal-phase (NP) system is used, e.g. on silica gel with a non-aqueous mobile phase, and in the second direction a reversed-phase (RP) system is applied [4]. This can be done by using a single cyanopropyl coated silica layer, on which TLC can be performed either in the reversed-phase mode (with an aqueous mobile phase) or in the normal-phase mode (using a nonpolar solvent) [4].

The great advantage of $2 \mathrm{D}$-TLC is its ability to separate many compounds. The drawback is that quantitative evaluations are difficult and don't meet current standards. Generally, TLC scanners which are available for densitometric measurements cannot be adapted easily to twodimensional TLC.

The purpose of this publication is to present a method for sensitive quantification of 2D-HPTLC separations, simultaneously measured at different wavelengths.

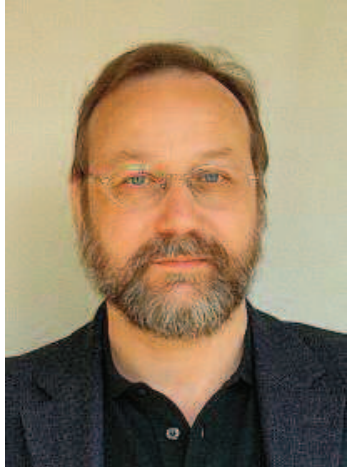

The separation of 12 sulphonamides with similar structure is presented as an example. The method can be used to quantify sulphonamides in the effluent of wastewater treatment plants.

\section{Results and discussion}

Sulphonamides were the first synthetic drugs with antimicrobial properties and some of these compounds are still in use. Worldwide, large amounts of highly diluted sulphonamides are being released into the environment. It is not easy to separate sulfonamides because they all have very similar structures. That is the reason why we decided to use 12 sulfonamides as model compounds to show the performance of the new 2D-scanner.

For direct spectrophotometry of HPTLplates, a TIDAS TLC 2010 system (J\&M

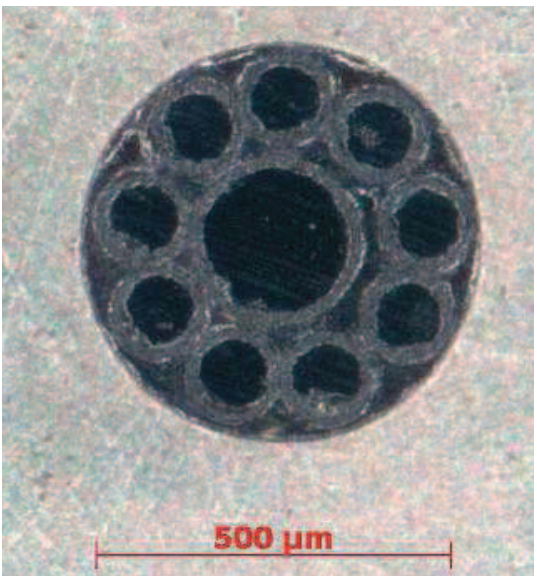

Fig. 3.3-1: Light fibre interface consisting of a $200 \mu \mathrm{m}$ inner core, surrounded by nine light fibres with a diameter of $100 \mu \mathrm{m}$ each 
Aalen, Germany) was used with an reflection attachment of 9 identical optical fibers (Figure 3.3-1) with a diameter of $100 \mu \mathrm{m}$ each (produced by TransMITCentre for Fibre Optics and Industrial Laser Applications, Gießen, Germany).

These fibers were used for illumination purposes and were circled around a single fiber with a diameter of $200 \mu \mathrm{m}$. This fiber transports the reflected light from the plate to the detector. A TIDAS-system with a wavelength resolution of $0.8 \mathrm{~nm}$ was used for detection. The interface is fixed at a distance of $450 \mu \mathrm{m}$ above the plate surface. During measurements, the plate is moving underneath this interface with constant velocity. The measurement time for a single spectrum (measured by a Tidas TLC 2010 device) in the wavelengths range from 190 to $1000 \mathrm{~nm}$ is $100 \mathrm{msec}$.

For fluorescence evaluation an LED (model: LEDMOD 365.1, produced by Omicron Laserage, Rodgau, Germany) was used instead of a deuterium lamp. The plate was illuminated at $365 \mathrm{~nm}$ using a measurement time of 0.1 seconds per spectrum.

The mixture of 12 sulphonamides was applied as a $3 \mathrm{~mm}$ band on a cyanopropyl-coated silica gel plate in the amounts of $2 \mu \mathrm{g}$ per sulphonamide, each. In the first direction the solvent mix of methyl tert-butyl ether, methanol, dichloromethane, cyclohexane, $\mathrm{NH}_{3} \quad(25 \%)$ $(48+2+2+1+1, v / v)$ was used. This is a normal phase separation. The plate was dried and in a second step the plate was developed with a solvent mix of water, acetonitrile, dioxane, ethanol $(8+2+1+1$, $\mathrm{v} / \mathrm{v})$. This is a typical reversed phase separation mode. The dried plate was scanned as described with the position of the application point at 342 rows consisting of 342 different data points. This resulted in a spatial resolution of 200 by $200 \mu \mathrm{m}$. The measurement time was $342 * 342 * 0.1 \mathrm{sec}=3$ h $25 \mathrm{~min}$. A scanned TLC-plate needs $400 \mathrm{MB}$ storage space. These data were copied into the computer memory to have rapid access to the data. The evaluation program was written in PureBasic (Ver. 4.50) and needed a 64 bit computer (HP EliteBook 2540p) to carry out the program.

Figure 3.3-2 shows a 3D plot (plate area and absorption intensities) at a given

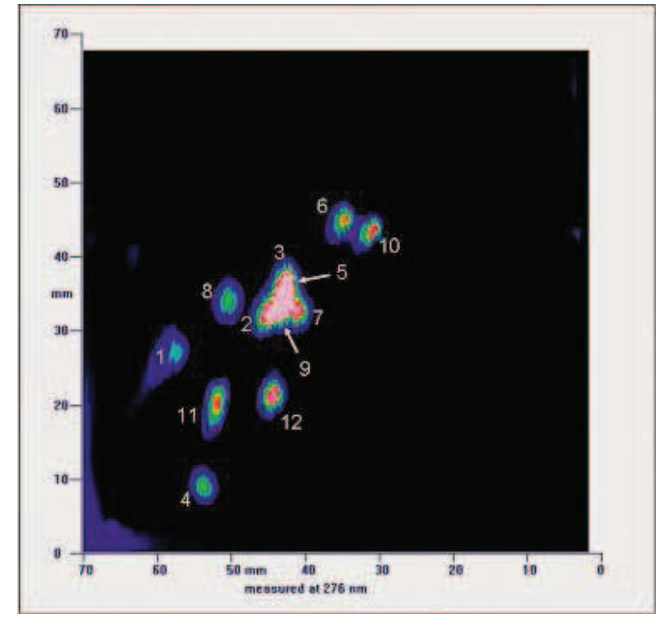

Fig. 3.3-2: Example of a 2D-HPTLC separation of 12 sulfonamides on a cyanopropyl plate measured in absorption at $276 \mathrm{~nm}$. The sulphonamides are: Sulphacarbamide (1), sulphadiazine (2), sulphadimidine (3), sulphaguanidine (4), sulphamerazine (5), sulphamethoxazole (6), sulphamethoxypyridazine (7), sulphanilamide (8), sulphapyridine (9), sulphaquinoxaline (10), sulphasomidine (11), and sulphathiazole (12)
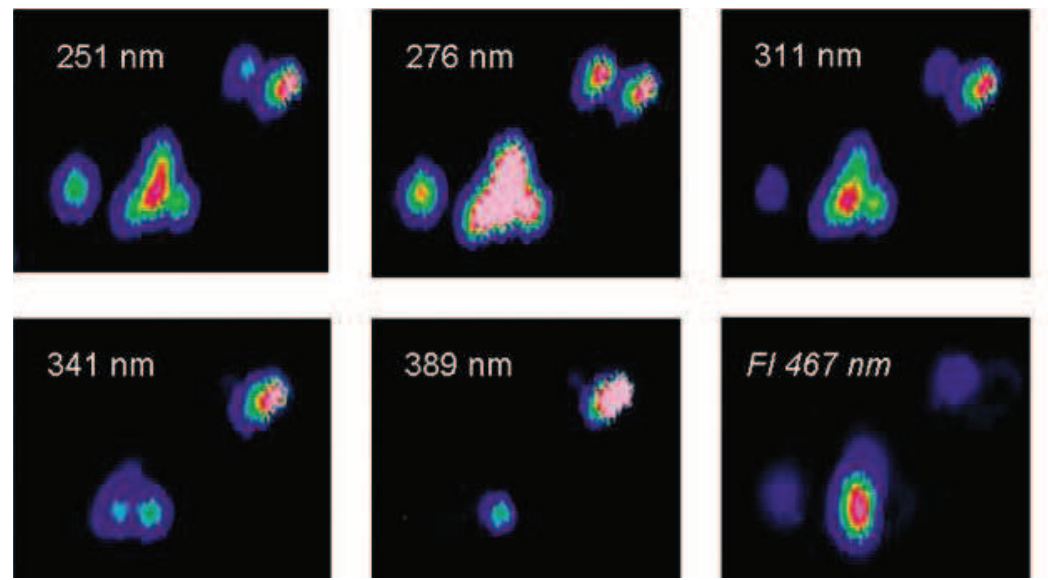

Fig. 3.3-3: The same area of interest measured at different wavelengths in absorption (1-5) and fluorescence (6) shows that this method can improve the spot resolution

wavelength. The date were evaluated using the following equation with a kfactor of $k=1$.

$T M D(k)=k\left(\frac{1}{R}-R\right)+(R-1)=\frac{a}{(1-a)}$

k: backscattering factor $(k \geq 0$ and $k \leq 1)$

a: absorption coefficient

$\mathrm{R}: \quad$ reflection $=\mathrm{I} / \mathrm{I}_{0}$

$\mathrm{I}$ : sample reflection

$\mathrm{I}_{0}$ : incident light

The program cursor can be moved over the screen to show the on-line spectrum measured at a particular plate position. The plot can be instantly changed by choosing another wavelength. In this way you can resolve neighbouring spots which are not spatially separated. In figure 3.3-3 the same area of interest is measured at different wavelengths, showing that the method can improve the spot resolution. The spectrum at a chosen separation is available simply by moving the cursor to its plate area position. A spot at a given wavelength can be virtually encircled and the resulting peak is integrated without any problems.
This makes the method a quantitative one, unique in 2D-TLC.

\section{References}

[1] Spangenberg B., Poole C.F., Weins C.: Quantitative Thin Layer Chromatography. A Practical Survey, Springer, Berlin, 2010

[2] Mondello L., Lewis A. C., Bartle K. D. (Editors): Multidimensional Chromatography, Wiley, Chichester, UK (2002)

[3] Mona Zakaria, Marie-France Gonnord, Georges Guichon: Applications of two-dimensional thin-layer chromatography, J. Chromatogr. 271 (1983) $127-192$

[4] Mirosław A. Hawrył, Anna Hawrył, Edward Soczewinski: Application of Normal- and Reversed-Phase 2D TLC on a Cyanopropyl-Bonded Polar Stationary Phase for Separation of Phenolic Compounds from the Flowers of Sambucus nigra L., J. Planar Chromatogr. 15 (2002) 4 - 10 